\title{
Trends in Childbearing, Marriage and Divorce in Sweden: An Update with Data up to 2012
}

\author{
GUNNAR ANDERSSON and MARTIN KOLK \\ Stockholm University Demography Unit, Sweden \\ Stockholm University SIMSAM Node for Demographic Research, Sweden
}

\section{Abstract}

We present an update of the main and parity-specific trends in vital family-demographic behavior in Sweden presented in Finnish Yearbook of Population Research 2011. Based on Swedish register data, previous time series of relative risks of childbearing, marriage, and divorce by calendar year are updated with another five years of observation. We demonstrate that more than a decade of increasing fertility levels turned into moderate fertility declines in 2011. This trend change pertains to all main birth orders. Marriage propensities continued to increase for mothers but stagnated for the childless. Since the turn of the century, trends in divorce risks seem to have leveled off, altogether reflecting a more prevalent role of marriage in recent Swedish family dynamics.

Keywords: fertility, marriage, divorce, Sweden

\section{Introduction}

Sweden and the other Nordic countries are frequently referred to as forerunners in family change. During the 1960s and 1970s they led the so-called Second Demographic Transition in family dynamics (Lesthaeghe 2010) with declining levels of fertility and marriage formation and increasing levels of divorce. However, since the 1980s the region has rather been renowned for its relatively high fertility levels (e.g., Hoem 2005). In more recent years, it has also caught attention to turnarounds in trends in marriage formation (Ohlsson-Wijk 2011, 2015) and the stabilization of divorce levels (Andersson and Kolk 2011). Thomson (2014) demonstrates how the Nordic countries led the trends of increasing "family complexity" during the second half of the twentieth century but that these trends seem to have leveled off at the turn of the new century (see also Statistics Sweden 2013). In recent theoretical arguments the relatively high fertility of the Nordic region and its recent trend reversals in family dynamics have been linked to the new gender regimes of that region. Esping-Andersen and Billari (2015) refer to the positive role of new equilibria in family relations in a more gender equal social setting; Goldscheider et al. (2015) similarly link recent family change in this region 
to what they label the second step in an ongoing "gender revolution". Still, seemingly conflicting developments can also be observed. For example, since 2010 total fertility has declined across the Nordic region (Table 1). These and other developments at the aggregate level make it the more pressing to study the underlying trends in groupspecific family-demographic behavior. The availability of excellent register data in Sweden and the other Nordic countries makes this task more rewarding than in other settings. In this contribution we provide an update of recent trends in childbearing and nuptiality in Sweden.

Table 1: Total Fertility Rates of the Nordic countries in 2010, 2012 and 2014

\begin{tabular}{llll}
\hline & $\mathbf{2 0 1 0}$ & $\mathbf{2 0 1 2}$ & $\mathbf{2 0 1 4}$ \\
\hline Sweden & 1.98 & 1.91 & 1.88 \\
Finland & 1.87 & 1.80 & 1.71 \\
Denmark & 1.88 & 1.73 & 1.69 \\
Norway & 1.95 & 1.85 & 1.76 \\
Iceland & 2.20 & 2.04 & 1.93 \\
\hline
\end{tabular}

\section{Our update: Data and Methods}

We provide an update of previous presentations of trends in family-demographic behavior of women in Sweden (Andersson 2001, Andersson 2004a, Andersson and Kolk 2011), covering childbearing and nuptiality developments up to 2012. These trends are presented in the form of a number of calendar-year series of relative risks of childbearing, marriage, and divorce (Figures 1-8). Our calculations are based on data derived from Swedish population registers, made available to us by Statistics Sweden. We analyze the longitudinal data on all births and civil-status changes in Sweden of all registered resident women in that country. Our childbearing analyses are based on women born in Sweden since 1925, with a presentation of childbearing trends during 1961-2012. Data on civil-status changes are complete from 1968 onwards; we study marriage formation and divorce during 1971-2012 of women born in Sweden after 1945.

Our presentation is based on event-history techniques in a manner first suggested by Hoem (1991a, 1993). We present family-demographic trends by providing time series of relative risks of the propensity of a woman to form a marriage, to divorce, or to give birth during a given calendar year - relative to a suitable baseline year. In our calculations, we standardize for the effects of a number of demographic background variables, which means that we control for the effect of compositional changes among women over the categories of these variables. We standardize for suitable representations of age, 
parity, premarital childbearing, and the durations since marriage formation, divorce, and any last previous birth; see Figures 1-8. We focus explicitly on the effect the number of previous live births has on demographic behavior by presenting separate time series of relative risks for women at different parities. For a thorough description of our system of period analysis, see Andersson (2001). Additional background information on Swedish divorce dynamics are available in Andersson (1997); related background information on patterns in marriage formation are provided by Andersson (1998) and Ohlsson-Wijk (2011); related information on childbearing dynamics are available in Andersson (1999).

\section{New trend development in Swedish fertility}

During the last half of a century, childbearing trends in Sweden have been highly volatile (for a comparison with the less strongly fluctuating childbearing trends in neighboring Denmark and Norway, see Andersson 2004b). With a temporary interruption in the late 1980s, the first-birth fertility of younger women declined continuously during three decades from the mid-1960s to 1998 when fertility postponement at the younger ages came to a halt. In response, from the early 1980s onwards it rose markedly for women in their 30 s and 40 s, altogether reflecting the general postponement of entry into motherhood and the recuperation of fertility at the higher ages (Figure 1, see also Billari et al. 2007). During the baby boom years of the 1980s, birth propensities increased for mothers as well (Figures 2-3). The 1990s, by contrast, was a period of baby bust, produced by declining childbearing propensities of women at all parities. We observe another uniform trend reversal towards the end of the 1990s: Birth propensities of mothers (Figures 2 3 ) and childless women aged 31 and above (Figure 1) experienced renewed increases after 1997. These rises continued until 2010 when yet another turnaround in Swedish roller-coaster fertility seems to have occurred. During 2011 childbearing propensities declined somewhat for the childless (Figure 1) as well as for mothers of one and two children (Figures 2-3). Evidently, trend reversals in Swedish fertility tend to be shared by women at all stages of the family life-cycle career. Previous research has demonstrated how these trends have evolved in tandem with the business cycle (Hoem 2000; Andersson 2000). The latest development is no exception to this pattern as it follows in the wake of increases in unemployment levels during 2009 and 2010 (OECD 2015). It remains to be seen if it amounts to a true trend reversal in Swedish fertility or merely is a short-term deviation in trends. 
Figure 1: Relative risk of first childbearing, by calendar year and age group. Swedish childless women, 1961-2012, standardized for age in single years. Rates relative to rates of younger women in 1977

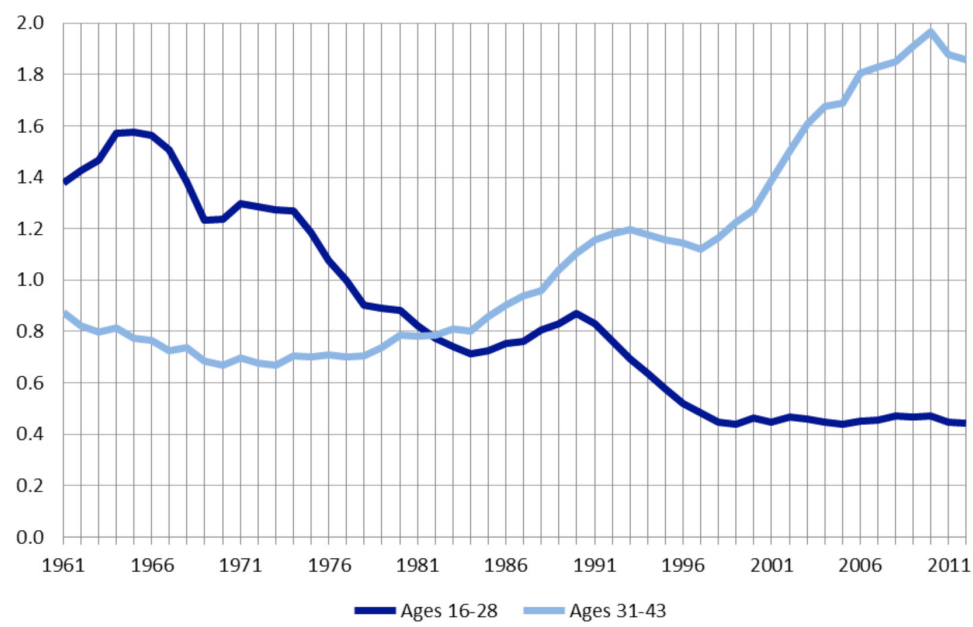

Figure 2: Relative risk of second, third and fourth birth, by calendar year. Swedish mothers, 1961-2012, standardized for age of mother and duration since previous birth. Rates relative to second-birth rates in 1977

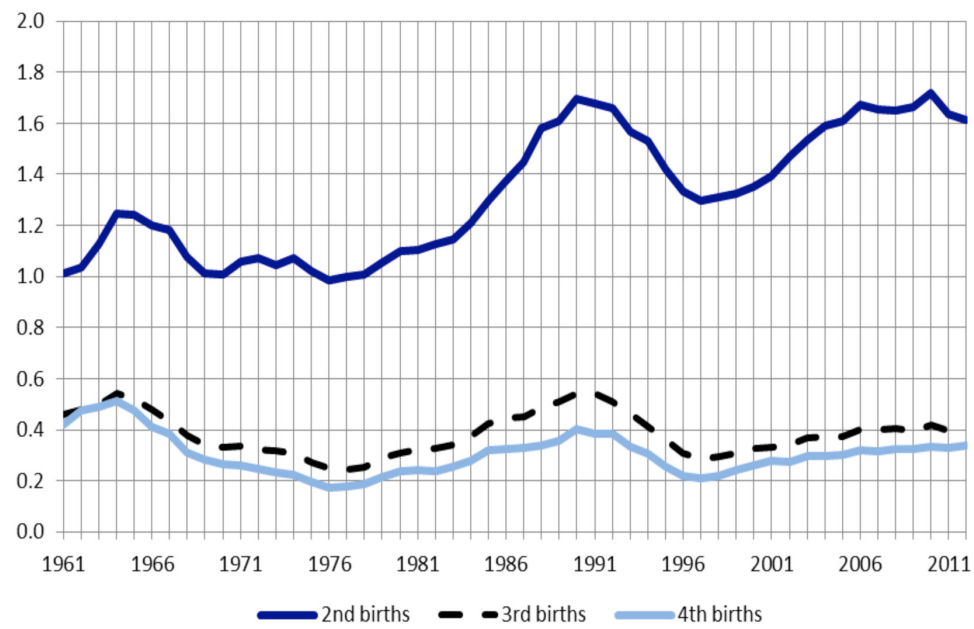


Figure 3: Relative risk of second, third and fourth birth, by calendar year. Swedish mothers, 1961-2012, standardized for age of mother and duration since previous birth. Rates relative to rates in 1977 for each birth order (separate models for each order)

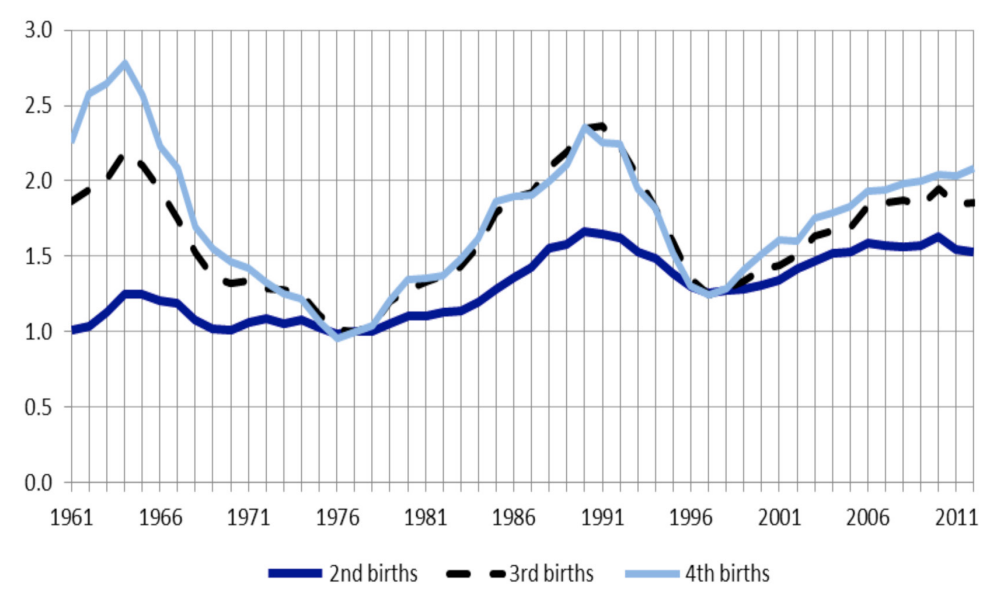

\section{Diverging trends in recent marriage formation}

During the 1970s, the propensity to marry decreased dramatically and continued to decline during the subsequent two decades, although at a much more moderate pace (Andersson 1998). In sharp contrast to this long-term trend, a spectacular but temporary rise in marriage propensities occurred in 1989 in response to the introduction of new rules concerning eligibility for a widow's pension (Hoem 1991b). Starting in 1999, we find a distinct trend reversal in marriage-formation propensities (cf. Ohlsson-Wijk 2011). The turn of the millennium appears to have triggered an additional number of people to marry in 2000, perhaps due to some digital preferences of people to marry in that year (Ohlsson-Wijk 2014). In each of the years from 2002 to 2008 marriage rates increased as well (Figure 4). Marriage propensities increased mainly for mothers so that the gap in first-marriage intensities between mothers and the childless has increased over time since the turn of the new millennium (Figure 5). A similar development can be observed for re-marriage propensities, which have increased for mothers but not for the childless (Figure 6). Evidently, marriage formation increasingly often appears at more advanced stages of women's family life-cycle careers, i.e., after becoming a parent (cf. Holland 2013). 
Figure 4: Relative risk of marriage formation, by calendar year. Never-married Swedish women, 1971-2012, standardized for parity and age. Rates relative to rates in 1980

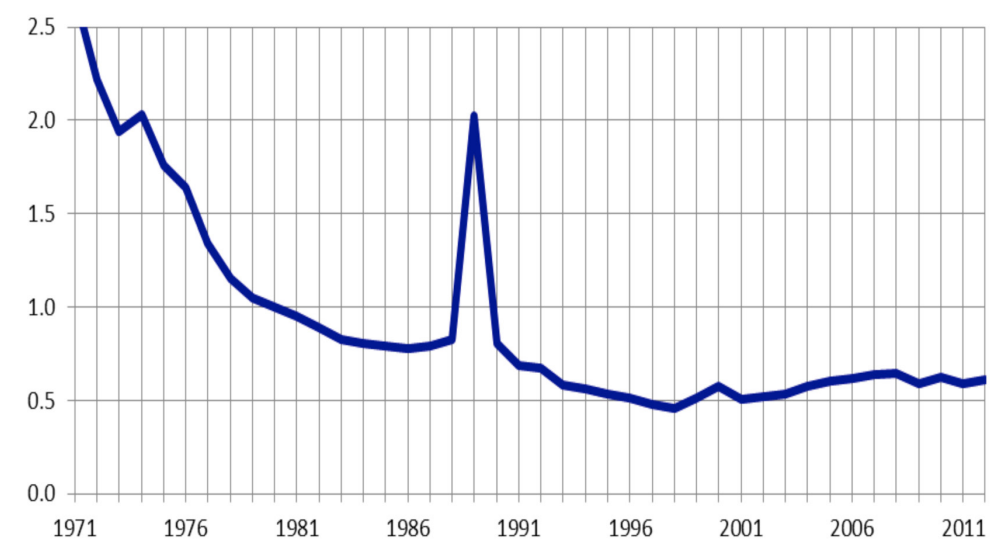

Figure 5: Relative risk of marriage formation, by parity and calendar year. Nevermarried Swedish women, 1971-2012, standardized for age. Rates relative to rates of one-child mothers in 1980

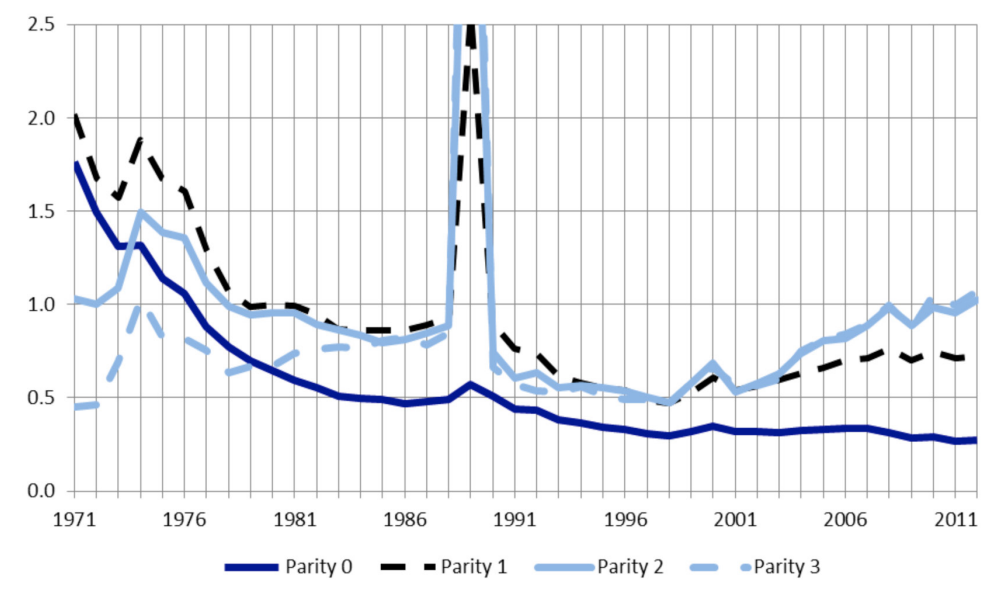


Figure 6: Relative risk of re-marriage, by parity and calendar year. First-divorced Swedish women, 1971-2012, standardized for age and time since divorce. Rates relative to rates of childless women in 1980

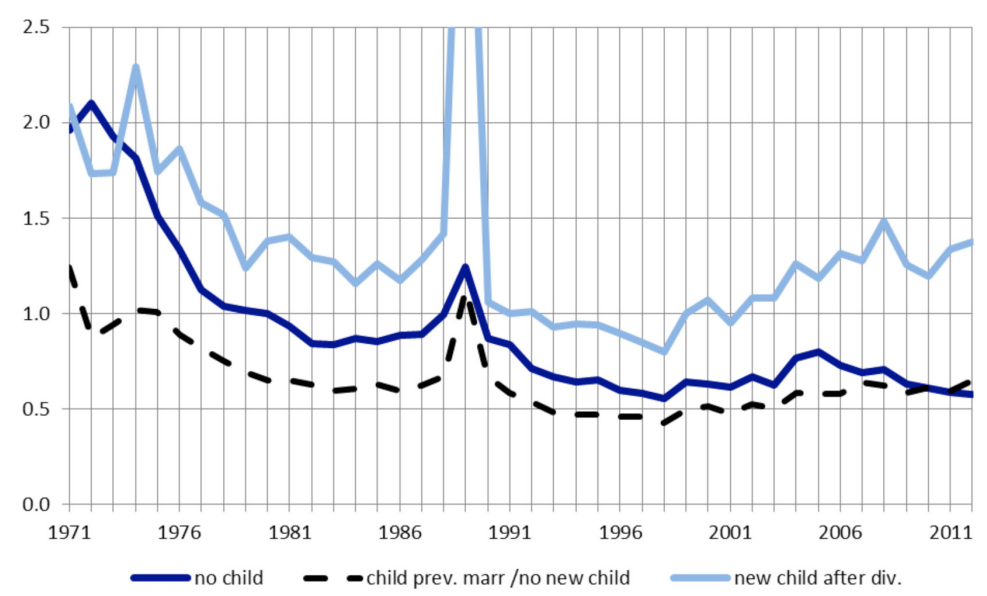

\section{Stabilization in Swedish divorce risks}

The divorce risk rose noticeably in 1974 in response to the liberalization of divorce legislation in that year. From the 1980s to the end of the 20th century, standardized divorce risks increased again but this time more gradually ${ }^{1}$ (Andersson 1997). To a large extent, the rise in 1974 was due to a growing propensity for divorce among childless women, the later increase can be attributed to a rise in divorce risks among mothers, who constitute the vast majority of married women. Interestingly, we note a recent trend break in divorce risks as well. Since the turn of the new century divorce risks no longer increase (Figure 7). This trend change is mainly due to the leveling off in divorce risks among two- and three-child mothers (Figure 8). Seen together with the trend reversals in marriage formation we note that Swedish family dynamics increasingly seems to have become characterized by more marriage oriented behaviors.

1 The increase in divorce risks mainly holds for age-standardized rates like those presented here. A counter-acting trend of marriage formation at increasingly high ages help keep crude divorce rates at more stable levels. 
Figure 7: Relative risk of divorce, by calendar year. First-married Swedish women, 1971-2012, standardized for age, parity, premarital childbearing, duration since previous birth, and duration of marriage. Rates relative to rates in 1980

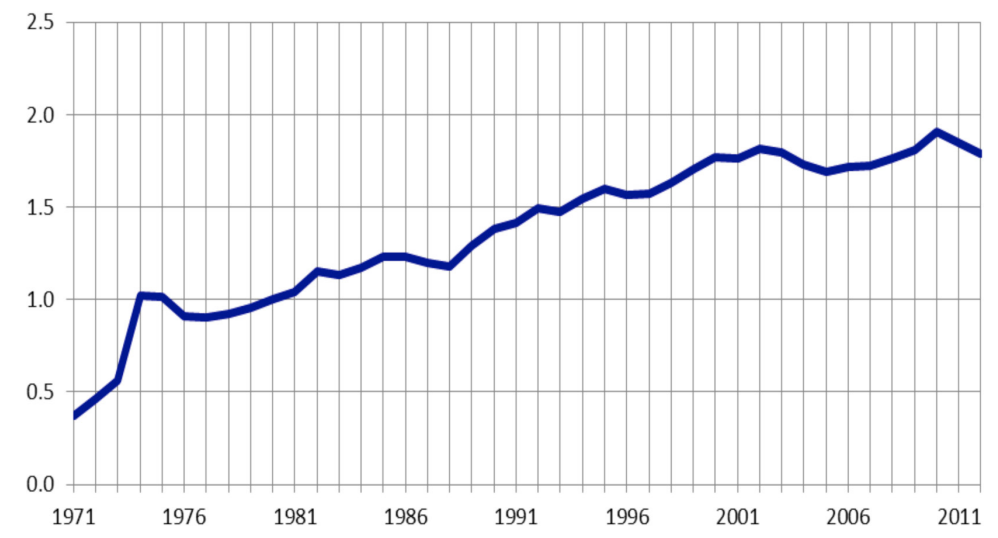

Figure 8: Relative risk of divorce, by parity and calendar year. First-married Swedish women, 1971-2012, standardized for age and duration of marriage. Risks for mothers also standardized for duration since previous birth and premarital childbearing. Rates relative to rates for one-child mothers in 1980

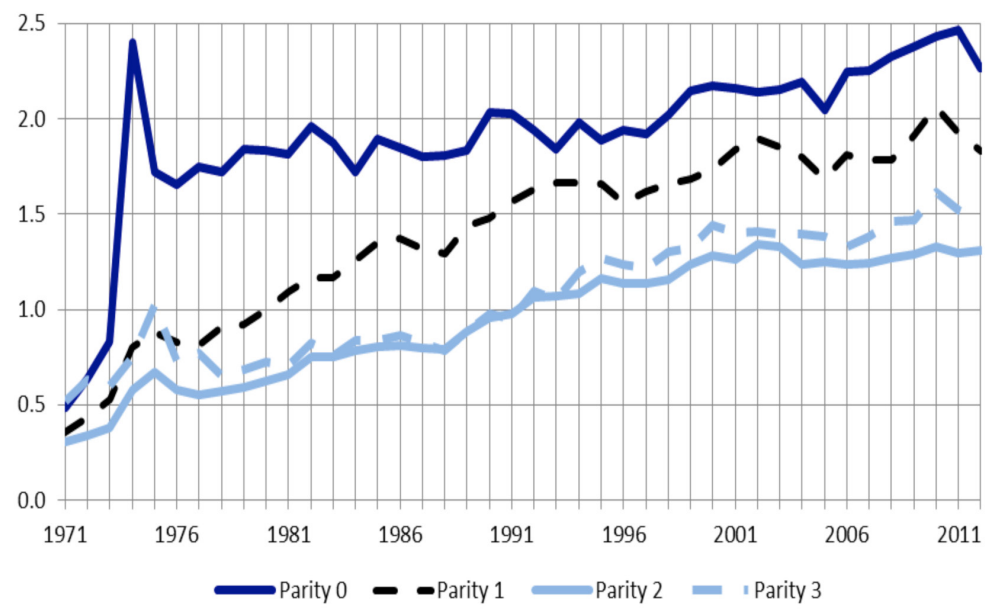




\section{Summary}

In this presentation, we provided an update of previously documented time series of relative risks of childbearing, marriage formation and divorce in Sweden, adding the years 2008-2012 to the picture. Our update demonstrates the persistence of the recent trend reversal in marriage formation and leveling off in divorce risks in Sweden, which taken together provides new input to recent debate about the nature of Nordic family dynamics and its signs of increasing family stability (cf. Esping-Andersen and Billari 2015, Goldscheider et al. 2015). We note that the renewed prominence of marriage is centered around couples with two or more children. This development may be hard to interpret in terms of concepts based on the so-called Second Demographic Transition; it remains for future research to detect to what extent it may be linked to increasingly gender equal behaviors in Swedish dual-earner dual-carer families.

In our update, we also demonstrated a very recent trend break in Swedish fertility, a change that coincided with new increases in unemployment rates across the Nordic region (OECD 2015). This development is also reflected in decreasing total fertility in the other Nordic countries (Table 1) as well as in parity-specific fertility in Iceland (Jónsson 2015), the Nordic country that was hardest hit by the latest economic crisis. It brings the issue of economic uncertainty in relation to Europe's economic crises (Kreyenfeld et al. 2012) back to the agenda of Nordic demographic research. Evidently, it will be interesting to keep monitor Swedish family-demographic trends also in the near future.

\section{Acknowledgements}

We are grateful for financial support from the Swedish Research Council, Vetenskapsrådet, via the Swedish Initiative for research on Microdata in the Social and Medical Sciences, SIMSAM, grant registration number 340-2013-5164. We thank Oskar Adenfelt for assistance with the graphical production.

\section{References}

Andersson, Gunnar, 1997. The impact of children on divorce risks of Swedish women. European Journal of Population 13: 109-145.

Andersson, Gunnar, 1998. Trends in marriage formation in Sweden 1971-1993. European Journal of Population 14: 157-178.

Andersson, Gunnar, 1999. Childbearing trends in Sweden 1961-1997. European Journal of Population 15: 1-24.

Andersson, Gunnar, 2000. The impact of labour-force participation on childbearing behavior: Procyclical fertility in Sweden during the 1980s and the 1990s. European Journal of Population16(4): 293-333.

Andersson, Gunnar, 2001. Trends in childbearing and nuptiality in Sweden, 1961(71)-1997. In: Tedebrand, L.-G., Sköld, P. (Eds.): Nordic Demography in History and Present-day Society. Umeå, Sweden: Umeå University, 67-100.

Andersson, Gunnar, 2004a. Demographic trends in Sweden: An update of childbearing and nuptiality up to 2002. Demographic Research 11(4): 95-110. 
Andersson, Gunnar, 2004b. Childbearing developments in Denmark, Norway, and Sweden from the 1970s to the 1990s: A comparison. Demographic Research Special Collection 3(7): 155-176.

Andersson, Gunnar, and Martin Kolk, 2011. Trends in childbearing and nuptiality in Sweden: An update with data up to 2007. Finnish Yearbook of Population Research 2011: 21-29.

Esping-Andersen, Gøsta, and Francesco Billari, 2015. Re-theorizing family demographics. Population and Development Review 41(1): 1-31.

Billari, Francesco, Hans-Peter Kohler, Gunnar Andersson, and Hans Lundström, 2007. Approaching the limit: Long-term trends in late and very late fertility. Population and Development Review 33(1): 149-170.

Goldscheider, Frances, Eva Bernhardt, and Trude Lappegård, 2015. The Gender Revolution: A framework for understanding changing family and demographic behavior. Population and Development Review 41(2): 207-239.

Hoem, Britta, 2000. Entry into motherhood in Sweden: The influence of economic factors on the rise and fall in fertility, 1986-1997. Demographic Research [Online] 2(4).

Hoem, Jan M., 1991a. La standardisation indirecte améliorée et son application à la divortialité en Suède (1971-1989). Population 46: 1551-1568.

Hoem, Jan M., 1991b. To marry, just in case ...: the Swedish widow's-pension reform and the peak in marriages in December 1989. Acta Sociologica 34: 127-135.

Hoem, Jan M., 1993. Classical demographic methods of analysis and modern event-history techniques. IUSSP: 22nd International Population Conference, Montreal, Canada, Volume 3: 281-291.

Hoem, Jan M., 2005. Why does Sweden have such high fertility? Demographic Research 13(22): 559-572.

Holland, Jennifer, 2013. Love, marriage, then the baby carriage? Marriage timing and childbearing in Sweden. Demographic Research 29(11): 275-306.

Jónsson, Ari, 2015. Childbearing Trends in Iceland, 1982-2013: Critical Junctures and Fertility Developments in a Nordic Context. Master Thesis, Stockholm University.

Kreyenfeld, Michaela, Gunnar Andersson, and Ariane Pailhé, 2012. Economic Uncertainty and Family Dynamics in Europe. Edited Special Collection 12 of Demographic Research.

Lesthaeghe, Ron, 2010. The unfolding story of the Second Demographic Transition. Population and Development Review 36(2): 211-251.

OECD, 2015. Unemployment rate (indicator). doi: 10.1787/997c8750-en.

Ohlsson-Wijk, Sofi, 2011. Sweden's marriage revival: An analysis of the new-millennium switch from long-term decline to increasing popularity. Population Studies 65(2): 183-200.

Ohlsson-Wijk, Sofi, 2014. Digit preferences in marriage formation in Sweden: Millennium marriages and birthday peaks. Demographic Research 30(25): 421-432.

Ohlsson-Wijk, Sofi, 2015. Family Formation in Sweden at the Turn of the New Millenium. Stockholm University Demography Unit Dissertation Series: 13.

Statistics Sweden, 2013. Barnafödande i nya relationer [Childbearing in new relationshipsons]. Demografiska rapporter 2013:2.

Thomson, Elizabeth, 2014. Family complexity in Europe. Annals of the American Academy of Political and Social Science 654: 245-258. 